\title{
Risk factors of geriatric depression in rural China based on a generalized estimating equation
}

\author{
Dongdong Zhao, ${ }^{1, *}$ Caiyun Hu, ${ }^{2}, *$ Jian Chen, ${ }^{3}$ Bao Dong, ${ }^{1}$ Qiongqiong Ren, ${ }^{1}$ \\ Dandan Yu, Yuanyuan Zhao, ${ }^{1,4}$ Jie Li, ${ }^{1}$ Yujun Huang ${ }^{1,5}$ and Yehuan Sun ${ }^{1,6}$ \\ ${ }^{1}$ Department of Epidemiology and Health Statistics, Anhui Medical University, Hefei, China \\ ${ }^{2}$ The First Affiliated Hospital, Anhui University of Chinese Medicine, Hefei, China \\ ${ }^{3}$ Ma'anshan Center for Disease Control and Prevention, Ma'anshan, China \\ ${ }^{4}$ The Fifth Sanatorium for Retired Cadres, Anhui Provincial Military Region, Hefei, China \\ ${ }^{5}$ Chawan Institute of Health, Demonstration District, Ma'anshan, China \\ ${ }^{6}$ Centre for Evidence-Based Practice, Anhui Medical University, Hefei, China
}

ABSTRACT

Background: The number of elderly individuals living in China is increasing rapidly. The aim of this study was to examine the potential risk factors of geriatric depression in rural areas.

Methods: A repeated cross-sectional study was conducted between January 2015 and October 2016 in rural China. Nine hundred forty-five elderly individuals were included in both investigations. A generalized estimating equation (GEE) was used to examine the relationships between geriatric depression and socio-demographics, the number of chronic diseases, ADL (Activity of Daily Living) disability, cognitive impairment, and anxiety.

Results: Among the participants, the majority was female (61.4\%) and illiterate $(81.5 \%)$ and had a general economic status $(63.0 \%)$ and more than two kinds of chronic diseases $(62.9 \%)$. The bivariate analysis indicated that geriatric depression was associated with social support, education level, economic status, ADL disability, anxiety disorders, and cognitive impairment at both survey time points. The GEE results showed that poor economic status $(\mathrm{OR}=8.294, \mathrm{p}<0.001)$, the presence of more than two chronic diseases $(\mathrm{OR}=$ $1.681, \mathrm{p}=0.048)$, ADL disability $(\mathrm{OR}=2.184, \mathrm{p}<0.001)$, cognitive impairment $(\mathrm{OR}=1.921, \mathrm{p}<0.001)$, and anxiety $(\mathrm{OR}=5.434, \mathrm{p}<0.001)$ were risk factors for geriatric depression in rural China; better social support $(\mathrm{OR}=0.924,95 \% \mathrm{CI}=0.899-0.949, \mathrm{p}<0.001)$ was found to be a protective factor.

Conclusions: Geriatric depression in rural China was associated with several socio-demographic, physical, and mental factors. Targeted interventions are essential to improve the psychological health of aged individuals in rural China.

Key words: geriatric depression, rural area, activity of daily life, anxiety, social support

\section{Introduction}

Societies with older ages are growing around the globe, especially in low- and middle-income countries (United Nations, 2014). It is expected that the proportion of people over the age of 60 years will reach $22 \%$ worldwide by 2050 , totaling a startling 2 billion people (WHO Ageing and Life Course, 2015). In China, there were

Correspondence should be addressed to: Yehuan Sun, Department of Epidemiology and Health Statistics, School of Public Health, Anhui Medical University, No. 81, Meishan Road, Hefei, Anhui 230032, China. Phone/Fax: +86-551-65167725. Email: yhsun_ahmu_edu@yeah.net. Received 27 Jul 2017; revision requested 12 Nov 2017; revised version received 6 Dec 2017; accepted 12 Dec 2017. First published online 30 January 2018.

* Dongdong Zhao and Caiyun Hu contributed equally to this work.
222 million people who were 60 years of age or older at the end of 2015 (China National Bureau of Statistics, 2015). In addition, $60 \%$ of the elderly are scattered in rural areas (Xie et al., 2010). Disparities between the inhabitants of rural and urban areas of China in terms of lifestyle, tradition, health awareness, economic factors, health services, and social and infrastructural support most assuredly exist (Wang, 2004). Elderly individuals living in rural areas without retirement allowances usually receive poorer quality health services and social support (Akhtar et al., 2013). Therefore, the mental and physical conditions of the elderly living in rural areas of China are important issues that cannot be overlooked. 
The elderly are especially vulnerable to psychological disorders. Among the typical psychiatric problems ailing the elderly, depression is generally the most common one (Moss et al., 2012). Depression is characterized by loss of interest, fatigue, and feelings of worthlessness and guilt and was reported to be ranked first in the global disease burden in terms of disability-adjusted life years (DALYs) by 2030 (World Health Organization, 2012). The prevalence of depressive symptoms among the elderly is high: $23.3 \%$ in southern Brazil (Goes et al., 2017), 36.7\% in Iran (Taheri Tanjanai et al., 2017), and $11.4 \%$ in India (Behera et al., 2016). Data drawn from the second wave of the China Health and Retirement Longitudinal Study (CHARLS) showed that more than $32.55 \%$ of the elderly in China had depression (Xu et al., 2016). Depressive disorder is also a first-line cause of mortality (Kuehner, 2003) and disability in the aged population (Blazer et al., 2001). Hypertensive patients with depressive disorder have a higher risk of sudden cardiac death (Ma et al., 2015). Late-life depression could increase the risk of dementia (Jorm, 2000). Patients with depression in the senior age group were found to be more likely to commit suicide than depressed patients in other age groups (Xu et al., 2000). A burgeoning aging population, together with a high prevalence of geriatric depression, will inevitably lead to a tremendous burden not only on individuals and families, but also on governments and societies. Monitoring and taking command of geriatric depression are essential.

However, a very few longitudinal studies have focused on geriatric depressive symptoms in rural areas of China. Moreover, there is a high proportion of illiterate individuals in rural China. Against this background and based on our research group's large-sample, cross-sectional study on the elderly (Zhao et al., 2017), this longitudinal study was carried out to determine the effects of different factors (including social-demographics, activities of daily living, social support, cognitive function, and anxiety) related to depression among the aged population in rural China.

\section{Methods}

\section{Participants}

A repeated cross-sectional study survey was performed in the rural region of Ma'anshan City, Anhui Province. The participants were recruited using a cluster sampling method. A total of 3,182 older adults were successfully interviewed at the baseline. Both the recruitment of the baseline participants and the study design were described extensively in our research group's previous study (Zhao et al., 2017). We conducted the second investigation using the same design and data collection procedures. A total of 3,048 older adults were successfully interviewed the second time. Because of the new administrative district division, ultimately, a total of 945 elderly people completed both records. This study was approved by the Ethics Committee of Anhui Medical University, Hefei, China.

\section{Procedure}

Informed consent was obtained from all the included participants. At baseline, a house-tohouse and face-to-face investigation was performed by public health postgraduate and undergraduate students. They were all coached by professional investigators before the interview. The participants were asked to provide information regarding their socio-demographic characteristics, social support, chronic diseases, activities of daily living, cognitive function, anxiety, and depression disorder. For illiterate individuals, some of these terminologies may have been difficult to understand. Thus, we transformed these self-reported questions to ask them neutral, straightforward questions in the local dialect. One year later, the participants were invited to complete the same questionnaires again at the second assessment.

\section{Instruments}

SOCIAL DEMOGRAPHIC QUESTIONNAIRE

A self-compiled demographic data questionnaire, including questions on gender (male, female), age (years), educational level (illiteracy, primary school, secondary school, high school or above), selfperceived economic status (good, middle, poor), and the number of chronic diseases $(0,1, \geq 2)$, was administered to the participants.

\section{GERIATRIC DEPRESSION SCALE-15 (GDS-15)}

The GDS-15 scale (Sheikh and Yesavage, 1986), extracted from the GDS-30, contains 15 items. A systematic review suggested that the GDS has good validity within the Chinese population: Cronbach's $\alpha$ for the GDS was higher than 0.85, and the test-retest reliability was higher than 0.73 (Sun et al., 2017). Moreover, a high correlation exists between the two scales $(r=0.66, \mathrm{p}<0.001)$ (Chan, 1996). This scale is frequently used as a special instrument for screening elderly patients with depression. The older adults were asked to express their feelings from the prior week using the GDS-15. Every item included two answers, namely, yes and no. The scores varied from zero to fifteen. Generally, a GDS-15 score of $0-7$ is 
considered normal and a GDS-15 score of 815 is considered depression, with higher scores indicating more severe depression.

\section{SOCIAL SUPPORT RATING SCALE (SSRS)}

The SSRS (Xiao, 1993) contains ten items and explores possible situations related to the following three subscales: (1) objective support (scores ranging from 1 to 22 ); (2) subjective support (scores from 8 to 32); and (3) support utilization (from 3 to 12). The item scores of the SSRS were simply added up (ranging from 12 to 66). Higher scores represented greater social support. This instrument had an internal consistency ranging from $\alpha=0.89$ to 0.94 in the Chinese population.

\section{ACTIVITY OF DAILY LIVING (ADL) SCALE}

The ADL scale (Lawton and Brody, 1969) consists of the following two sections, with a total of 14 items: the physical self-maintenance scale, which included six items, and the instrumental activities of daily living scale, which included eight items. Each activity is evaluated by a scoring system ranging from 1 (independent execution of activities) to 4 (full dependence) points. The scale range is 14-56 points; scores $<15$ are considered to be in the normal range, and scores $\geq 15$ indicate different degrees of $\mathrm{ADL}$ functional decline.

\section{ZUNG SELF-RATING ANXIETY SCALE (SAS)}

The SAS (Zung, 1971) was used to assess the levels of anxiety of the participants. This scale includes 20 questions, with each response using a 4-point scale ranging from "none" to "most of the time," the standardized score of which is equal to the raw score times 1.25 (range 0-100). A total point score less than 50 represented no anxiety, whereas anything above 50 represented mean anxiety disorder. The internal reliability (alpha) of the Chinese version of the SAS is 0.93, and the validity (correlation with the Global Assessment Scale) is 0.71 ( $\mathrm{Li}$ et al., 2012).

\section{Mini-Mental state examination (MMSE)}

Cognitive function was measured using the Chinese version of the MMSE (Katzman et al., 1988). Participants' orientation, memory, attention, calculation, language, and written and visual construction abilities were assessed using the MMSE. This scale consists of 30 items, with scores ranging from 0 to 30 . Cognitive decline was defined as a decline in the MMSE score $\geq 3$ points at followup (Llewellyn et al., 2010). The widely accepted cut-off score of cognitive impairment in China is education-specific, namely, 17 for illiteracy, 20 for primary school, and 24 for at least middle school.

\section{Statistical analysis}

The obtained results were analyzed with SPSS (version 11.0). First, descriptive analyses were performed to determine the distribution of the demographic factors at baseline. The means (SD) were reported for continuous variables, and the number (percentage) was presented for categorical variables. To compare the elderly who had depression with those without depression at baseline, we performed $\chi^{2}$ tests and $t$ tests. According to this research design, second, generalized estimation equation (GEE) models with $\log$ links having robust variances were used to examine the association of the selected variables with geriatric depression. This approach accounts for the correlation between the repeated measures within a person. The GEE parameter estimates were expressed as the coefficients $(\beta)$ and the $95 \%$ confidence intervals (95\% CIs). A p-value $<0.05$ was considered to indicate statistical significance.

\section{Results}

\section{Demographic characteristics}

At the first survey (S1), the gender distribution was $38.6 \%$ male and $61.4 \%$ female. The age range was from 60 to 95 years, with a mean age of 72 years. Illiteracy was the most frequent education status $(81.5 \%)$. Regarding self-reported economic status, $63.0 \%$ of the participants were at a general level $(31.1 \%$ were poor, only $5.9 \%$ were good). More than half of the participants $(62.9 \%)$ had at least two kinds of chronic diseases. Detailed characteristics of the participants are presented in Table 1.

\section{Change in geriatric depression}

During the two assessments, 45 (4.8\%) individuals had consistent geriatric depression, and 682 $(72.2 \%)$ study participants did not have depressive symptoms at the baseline survey (S1) nor at the second survey (S2) period. One hundred thirtythree $(14.1 \%)$ individuals exhibited depression at the first survey but then no longer met the diagnostic criteria for depression at the final survey. In contrast, $85(9.0 \%)$ elderly people without depression at $\mathrm{S} 1$ were diagnosed as having depression at S2. The characteristics of the participants with different depression statuses are shown in Table 2.

\section{Characteristics of the participants with different depression statuses}

The mean age of the no depression group was the lowest $(70.7 \pm 6.3$ years), while that of 
Table 1. Characteristics of participants with and without depression

\begin{tabular}{|c|c|c|c|c|c|c|c|c|c|}
\hline \multirow[b]{2}{*}{ VARIABLES } & \multirow{2}{*}{$\begin{array}{l}\text { ALL OF } \\
\text { SAMPLE } \\
945\end{array}$} & \multicolumn{4}{|c|}{ GERIATRIC DEPRESSION AT S 1} & \multicolumn{4}{|c|}{ GERIATRIC DEPRESSION AT S 2} \\
\hline & & $\begin{array}{l}\text { YES } \\
(N=178)\end{array}$ & $\begin{array}{l}\text { No } \\
(N=767)\end{array}$ & $t / \chi 2$ & $p$ & $\begin{array}{l}\text { YES } \\
(N=130)\end{array}$ & $\begin{array}{l}\text { No } \\
(N=815)\end{array}$ & $t / \chi^{2}$ & $p$ \\
\hline Age, mean(SD) & $71.1(6.3)$ & $72.8(6.3)$ & $70.7(6.3)$ & $-3.92 *$ & $<0.001$ & $73.4(6.4)$ & $72.3(6.4)$ & -1.75 & 0.080 \\
\hline Gender, $\%$ & & & & 2.78 & 0.096 & & & 2.29 & 0.130 \\
\hline Male & $365(38.6)$ & $59(33.1)$ & $306(39.9)$ & & & $42(32.3)$ & $320(39.3)$ & & \\
\hline Female & $580(61.4)$ & $119(66.9)$ & $461(60.1)$ & & & $88(67.7)$ & $495(60.7)$ & & \\
\hline Education, \% & & & & 9.76 & 0.008 & & & 7.39 & 0.025 \\
\hline Illiteracy & $770(81.5)$ & $158(88.8)$ & $612(79.8)$ & & & $107(82.3)$ & $593(72.8)$ & & \\
\hline Primary & $129(13.7)$ & $18(10.1)$ & $111(14.5)$ & & & $21(16.2)$ & $168(20.6)$ & & \\
\hline $\begin{array}{l}\text { At least middle } \\
\text { school }\end{array}$ & $46(4.9)$ & $2(1.1)$ & $44(5.7)$ & & & $2(1.5)$ & $54(6.6)$ & & \\
\hline \multicolumn{2}{|l|}{ Economic status, $\%$} & & & 89.40 & $<0.001$ & & & 73.76 & $<0.001$ \\
\hline Poor & $294(31.1)$ & $107(60.1)$ & $187(24.4)$ & & & $99(76.2)$ & $297(36.4)$ & & \\
\hline General & $595(63.0)$ & $70(39.3)$ & $525(68.4)$ & & & $28(21.5)$ & $406(49.8)$ & & \\
\hline Good & $56(5.9)$ & $1(.6)$ & $55(7.2)$ & & & $3(2.3)$ & $112(13.7)$ & & \\
\hline \multicolumn{2}{|c|}{ Chronic diseases, $\%$} & & & 12.15 & 0.002 & & & 5.92 & 0.052 \\
\hline No & $112(11.9)$ & $16(8.9)$ & $96(12.5)$ & & & $10(7.7)$ & $124(15.2)$ & & \\
\hline 1 & $239(25.3)$ & $30(16.9)$ & $209(27.3)$ & & & $42(32.3)$ & $269(33.0)$ & & \\
\hline$\geq 2$ & $594(62.9)$ & $132(74.2)$ & $462(60.2)$ & & & $78(60.0)$ & $422(51.8)$ & & \\
\hline \multicolumn{2}{|c|}{ ADL disabilities, $\%$} & & & 37.35 & $<0.001$ & & & 22.45 & $<0.001$ \\
\hline No & $323(34.2)$ & $26(14.6)$ & $297(38.7)$ & & & $21(16.2)$ & $305(37.4)$ & & \\
\hline Yes & $622(65.8)$ & $152(85.4)$ & $470(61.3)$ & & & $109(83.8)$ & $510(62.6)$ & & \\
\hline \multicolumn{2}{|l|}{ Anxiety, \% } & & & 144.05 & $<0.001$ & & & 40.40 & $<0.001$ \\
\hline No & $770(81.5)$ & $89(50.0)$ & $681(88.8)$ & & & $96(73.8)$ & $751(92.1)$ & & \\
\hline Yes & $175(18.5)$ & $89(50.0)$ & $86(11.2)$ & & & $34(26.2)$ & $64(7.9)$ & & \\
\hline \multicolumn{2}{|c|}{ Cognitive impairment, $\%$} & & & 16.94 & $<0.001$ & & & 43.28 & $<0.001$ \\
\hline No & $549(58.1)$ & $79(44.4)$ & $470(61.3)$ & & & $64(49.2)$ & $626(76.8)$ & & \\
\hline Yes & $396(41.9)$ & $99(55.6)$ & $297(38.7)$ & & & $66(50.8)$ & $189(23.2)$ & & \\
\hline $\begin{array}{c}\text { Social support, } \\
\text { mean(SD) }\end{array}$ & $31.6(5.4)$ & $29.4(5.8)$ & $32.1(5.2)$ & $5.7^{*}$ & $<0.001$ & $28.8(6.3)$ & $33.1(5.9)$ & 7.76 & $<0.001$ \\
\hline
\end{tabular}

${ }^{*} t$-test, the others are $\chi^{2}$ test.

the always depression group was the highest $(73.9 \pm 6.4$ years). The elderly who presented with depression throughout the study period had higher percentages of females $(68.9 \%)$, illiteracy $(88.9 \%)$, poor economic status $(62.2 \%)$, ADL disability (93.3\%) and cognitive impairment $(62.2 \%)$, and lower social support scores $(28.4 \pm 6.4)$.

\section{Factors associated with geriatric depression: bivariate analysis}

Table 1 also shows the characteristics of the 945 participants at the two assessments according to the presence or absence of geriatric depressive symptoms. The elderly with depression were of older ages and had more chronic diseases at S1. In both surveys, older individuals with geriatric depression had lower scores on social support, poorer education, and worse economic status and reported a greater proportion of ADL disability, anxiety disorders, and cognitive impairment.
Factors associated with geriatric depression: multivariate GEE analysis

The GEE suggested that geriatric depression was associated with economic status (poor: $\mathrm{OR}=$ 8.294, 95\% CI $=3.124-22.023, \mathrm{p}<0.001$; general: $\mathrm{OR}=2.791,95 \% \mathrm{CI}=1.057-7.372, \mathrm{p}=$ $0.038)$, the number of chronic diseases $(\geq 2$ : OR $=$ $1.681,95 \% \mathrm{CI}=1.004-2.814, \mathrm{p}=0.048)$, ADL dysfunction $(\mathrm{OR}=2.184,95 \% \mathrm{CI}=1.490-3.199$, $\mathrm{p}<0.001)$, anxiety $(\mathrm{OR}=5.434,95 \% \mathrm{CI}=3.866-$ 7.640, $\mathrm{p}<0.001)$, cognitive impairment $(\mathrm{OR}=$ $1.921,95 \% \mathrm{CI}=1.447-2.549, \mathrm{p}<0.001)$, and social support $(\mathrm{OR}=0.924,95 \%$ CI $=0.899$ $0.949, \mathrm{p}<0.001)$. The results of the GEE are shown in Table 3.

\section{Discussion}

In our study, the prevalence of geriatric depression in rural China was $18.8 \%$ at baseline and $13.8 \%$ at the second assessment. This was much higher 
Table 2. Characteristics of participants in different depression status at baseline

\begin{tabular}{|c|c|c|c|c|}
\hline & $\begin{array}{l}\text { NO } \\
\text { DEPRESSION }\end{array}$ & $\begin{array}{l}\text { ALWAYS } \\
\text { DEPRESSION }\end{array}$ & $\begin{array}{l}\text { DEPRESSION } \\
\text { ONLY BASELINE }\end{array}$ & $\begin{array}{l}\text { DEPRESSION } \\
\text { ONLY FOLLOW-UP }\end{array}$ \\
\hline$n$ & 682 & 45 & 133 & 85 \\
\hline Age, mean(SD) & $70.7(6.3)$ & $73.9(6.4)$ & $72.4(6.3)$ & $70.8(6.1)$ \\
\hline \multicolumn{5}{|l|}{ Gender, \% } \\
\hline Male & $277(40.6)$ & $14(31.1)$ & $45(33.8)$ & $29(34.1)$ \\
\hline Female & $405(59.4)$ & $31(68.9)$ & $88(66.2)$ & $56(65.9)$ \\
\hline \multicolumn{5}{|l|}{ Education, \% } \\
\hline Illiteracy & $541(79.3)$ & $40(88.9)$ & $118(88.7)$ & $71(83.5)$ \\
\hline Primary & $99(14.5)$ & $5(11.1)$ & $13(9.8)$ & $12(14.1)$ \\
\hline At least middle school & $42(6.2)$ & $0(0)$ & $2(1.5)$ & $2(2.4)$ \\
\hline \multicolumn{5}{|l|}{ Economic status, \% } \\
\hline Poor & $156(22.9)$ & $28(62.2)$ & $79(59.4)$ & $31(36.5)$ \\
\hline General & $471(69.1)$ & $17(37.8)$ & $53(39.8)$ & $54(63.5)$ \\
\hline Good & $55(8.1)$ & $0(0)$ & $1(0.8)$ & $0(0)$ \\
\hline \multicolumn{5}{|l|}{ Chronic diseases, $\%$} \\
\hline No & $93(13.6)$ & $7(15.6)$ & $9(6.8)$ & $3(3.5)$ \\
\hline 1 & $187(27.4)$ & $5(11.1)$ & $25(18.8)$ & $22(25.9)$ \\
\hline$\geq 2$ & $402(58.9)$ & $33(73.3)$ & $99(74.4)$ & $60(70.6)$ \\
\hline \multicolumn{5}{|l|}{ ADL disabilities, $\%$} \\
\hline No & $271(39.7)$ & $3(6.7)$ & $23(17.3)$ & $26(30.6)$ \\
\hline Yes & $411(60.3)$ & $42(93.3)$ & $110(82.7)$ & $59(69.4)$ \\
\hline \multicolumn{5}{|l|}{ Anxiety, \% } \\
\hline No & $608(89.1)$ & $30(66.7)$ & $59(44.4)$ & $73(85.9)$ \\
\hline Yes & $74(10.9)$ & $15(33.3)$ & $74(55.6)$ & $12(14.1)$ \\
\hline \multicolumn{5}{|l|}{ Cognitive impairment, $\%$} \\
\hline No & $419(61.4)$ & $17(37.8)$ & $62(46.6)$ & $51(60.0)$ \\
\hline Yes & $263(38.6)$ & $28(62.2)$ & $71(53.4)$ & $34(40.0)$ \\
\hline Social support, mean(SD) & $32.2(5.2)$ & $28.4(6.4)$ & $29.8(5.5)$ & $31.5(5.4)$ \\
\hline
\end{tabular}

than the prevalence of $6.0 \%$ that was reported in Chen's study in Yingshang County, Anhui Province (Chen et al., 2005), and slightly higher than the prevalence of $10.61 \%$ that was reported in Feng's study conducted in Xinjiang (Feng et al., 2014). However, it was lower than the prevalence of $36.94 \%$ that was found in a recent study conducted in Lengshuijiang City, Hunan Province ( $\mathrm{He}$ et al., 2016). Overall, a decline in the prevalence of depression was found in our study. Several explanations give rise to this prevalence change. First, a previous study indicated that elderly individuals living in rural areas were more likely to have poor-quality healthcare services, increased suffering from chronic diseases, and finally depression (Alexopoulos, 2005). Similarly, we found that the elderly individuals with more than two chronic diseases were more likely to have depression. In recent years, the perpetually sophisticated basic medical facilities and convenient transportation have brought to individuals more convenient and better medical treatment. Thus, aged individuals should have a better physical status and a lower risk of depression. Second, previous studies have suggested that depressive symptoms are more concentrated among aged individuals who live in disadvantaged economic situations (Yusuf et al., 2013; Xu et al., 2016). This notion is consistent with our finding that poor economic status may increase the risk of depression. With the development of industrialization, some elderly individuals have part-time jobs at nearby factories. In addition, poor elderly individuals can benefit from the anti-poverty project. A better income might lead to fewer psychosocial disorders. Third, we found that social support, similarly to an antecedent study (Chao, 2011), was highly associated with depressive symptoms. Increasing income support and greater concerns for weak, ill, and disabled aged individuals are buffers against depression in later life. Different measures of depressive symptoms were used, and thus direct comparisons should be made with caution. The improved conditions mentioned above may partly account for the difference. In addition, $4.8 \%$ of the individuals had consistent geriatric depression. This value is lower than that of Steinert's report, which reported that a percentage of $10-17 \%$ has a chronic course of depression in the general population (Steinert et al., 2014). 
Table 3. Multivariate analysis for associations between depression and covariates, performed by generalized estimating equations (GEE)

\begin{tabular}{|c|c|c|c|c|c|}
\hline & \multirow[b]{2}{*}{ OR } & \multicolumn{2}{|c|}{$95 \% \mathrm{CI}$} & \multirow[b]{2}{*}{ WALD $\chi^{2}$} & \multirow[b]{2}{*}{$p$-VALUE } \\
\hline & & LOWER & UPPER & & \\
\hline Age & 0.99 & 0.963 & 1.019 & 0.462 & 0.497 \\
\hline \multicolumn{6}{|l|}{ Gender } \\
\hline Female & 0.94 & 0.651 & 1.358 & 0.108 & 0.743 \\
\hline Male & Ref & & & & \\
\hline \multicolumn{6}{|l|}{ Education } \\
\hline Literacy & Ref & & & & \\
\hline Primary & 1.123 & 0.711 & 1.774 & 0.247 & 0.619 \\
\hline At least middle school & 0.484 & 0.159 & 1.48 & 1.617 & 0.204 \\
\hline \multicolumn{6}{|l|}{ Economic status } \\
\hline Poor & 8.294 & 3.124 & 22.023 & 18.029 & $<0.001$ \\
\hline General & 2.791 & 1.057 & 7.372 & 4.291 & 0.038 \\
\hline Good & Ref & & & & \\
\hline \multicolumn{6}{|l|}{ Chronic diseases } \\
\hline No & Ref & & & & \\
\hline 1 & 1.328 & 0.769 & 2.294 & 1.036 & 0.309 \\
\hline$\geq 2$ & 1.681 & 1.004 & 2.814 & 3.895 & 0.048 \\
\hline \multicolumn{6}{|l|}{ ADL disabilities } \\
\hline No & Ref & & & & \\
\hline Yes & 2.184 & 1.49 & 3.199 & 16.059 & $<0.001$ \\
\hline \multicolumn{6}{|l|}{ Anxiety } \\
\hline No & Ref & & & & \\
\hline Yes & 5.434 & 3.866 & 7.64 & 94.851 & $<0.001$ \\
\hline \multicolumn{6}{|l|}{ Cognitive impairment } \\
\hline No & Ref & & & & \\
\hline Yes & 1.921 & 1.447 & 2.549 & 20.419 & $<0.001$ \\
\hline Social support & 0.924 & 0.899 & 0.949 & 33.513 & $<0.001$ \\
\hline
\end{tabular}

Gender was found to be positively associated with depressive symptoms, namely women had a higher risk of suffering from depression (Zhang and $\mathrm{Li}, 2011$ ). Females are more sensitive to some key factors of depression, such as rejection, separation, and criticism (Martel, 2013). However, the present study reported a non-significant association between gender and depression. In addition, age and education level were not found to be factors influencing vulnerability to depression in later life. This finding is in line with Behera et al.'s (2016) study but is not consistent with Weyerer et al.'s (2008) paper. Kim et al.'s (2014) study also suggested that illiteracy in elderly individuals was associated with a higher rate, and increased severity of depression. A possible explanation of this finding could be that the proportion of illiteracy in our study was too high $(81.5 \%)$ to identify a relationship. In this study, the risk of later-life depression in a rural area of China was positively influenced by activity of daily living. A prior study (Schoevers et al., 2000) came to the same conclusion: ADL dysfunction was a risk factor of geriatric depression. When aged individuals are ADL disabled, they are in great need of help and care from others. In the rural area of this study, many young adults leave to earn their living. Nevertheless, there may be some disparities between rural and urban areas, such as a lack of volunteer organizations and community service centers in rural parts of the country. When ADL-disabled elderly feel incapable and hopeless, they are more likely to develop mental illnesses, including anxiety and depression.

Similar to the existing literature (Mirza et al., 2017), we found that cognitive impairment increased the risk of geriatric depression. Several studies came to the opposite conclusion, stating that later-life depression precedes the development of mild cognitive impairment (MCI) and is a potential risk factor of MCI (Spira et al., 2012; Steenland et al., 2012). However, there were also some explanations that could make our finding plausible. Elderly with cognitive impairment are frequently forgetful and cannot perform well in daily life. Some of them fear they will develop dementia. These negative feelings are easy triggers 
of psychiatric disorders. Moreover, Mirza et al. (2014) reported that later-life depression was a prodrome of dementia during short-term periods but not during long-term periods. This finding hinted that depression may be the intermediate stage between MCI and dementia. Several studies have shown that anxiety symptoms can predict later depressive symptoms across many time scales, ranging from hours to years (Starr and Davila, 2012; Jacobson and Newman, 2014; Starr et al., 2014). In the same way, we found that anxiety was a risk factor of depression among elderly individuals living in rural China. A possible mechanism underlying this association could be that anxiety may lead to interpersonal dysfunction, which in turn elevates the risk of depression.

The results from this analysis may provide important policy implications for mental health among the elderly in rural China. More rigorous studies targeting the risk factors, control, and prevention of geriatric depression are needed. It is, therefore, imperative to develop more appropriate mental healthcare strategies to care for these aged individuals, such as better income support, more complete healthcare facilities, and more physical infrastructure, in rural China.

Several methodological limitations of our study need to be noted. First, elderly individuals with communicative disorders were excluded. Accordingly, this study may have had limited power in determining some of the associations. Second, only two assessments were conducted. It is likely that we will perform more assessments in the future. Finally, some data, such as the chronic disease and economic status information, were based on self-reported information. The vulnerability of self-reported data to information bias should be acknowledged.

\section{Conclusion}

In conclusion, the prevalence of depression among the elderly in rural China was high. The GEE results of our study showed that geriatric depression was associated with economic status, the presence of more than two chronic diseases, ADL disability, impaired cognitive function, anxiety, and poor social support. Further studies with larger samples that focus on the mechanism are warranted to verify our findings and to prevent geriatric depression in rural areas.

\section{Conflict of interest}

None.

\section{Description of authors' roles}

D.D. Zhao and C.Y. Hu were responsible for the data analysis and for writing the paper; J. Chen and Y.J. Huang performed the cluster sampling; B. Dong, Q.Q. Ren, and D.D. Yu performed the data collection; Y.Y. Zhao and J. Li were responsible for the research design; and Y.H. Sun assisted in the critical revisions of the paper.

\section{Acknowledgments}

We would like to thank all the elderly who took part in this study. We also thank all the village doctors for their kind assistance with data collection. This research was supported by grants from the Talent Program of the Higher Education Revitalization Plan of Anhui Province, China, 2013 and the Major Program of the Humanities and Social Science of the Higher Education of Anhui Province, China, 2014 (SK2014ZD037).

\section{References}

Akhtar, H., Khan, A. M., Vaidhyanathan, K. V., Chhabra, P. and Kannan, A. T. (2013).

Socio-demographic predictors of depression among the elderly patients attending out patient departments of a tertiary hospital in North India. International fournal of Preventive Medicine, 4, 971-975.

Alexopoulos, G. S. (2005). Depression in the elderly. Lancet, 365, 1961-1970.

Behera, P., Sharan, P., Mishra, A. K., Nongkynrih, B., Kant, S. and Gupta, S. K. (2016). Prevalence and determinants of depression among elderly persons in a rural community from northern India. National Medical Fournal of India, 29, 129-135.

Blazer, D. G., Hybels, C. F. and Pieper, C. F. (2001). The association of depression and mortality in elderly persons: a case for multiple, independent pathways. Fournals of Gerontology. Series A, Biological Sciences and Medical Sciences, 56, M505-M509.

Chan, A. C. (1996). Clinical validation of the Geriatric depression scale (GDS): Chinese version. Fournal of Aging and Health, 8, 238-253.

Chao, S. F. (2011). Assessing social support and depressive symptoms in older Chinese adults: a longitudinal perspective. Aging Mental Health, 15, 765-774.

Chen, R., Wei, L., Hu, Z., Qin, X., Copeland, J. R. and Hemingway, H. (2005). Depression in older people in rural China. Fournal of Mental Health and Aging, 165, 2019-2025.

China National Bureau of Statistics (2015). The national economic and social development statistical bulletin in 2015. Available at: http://www.stats.gov.cn/tjsj/zxfb/201602/ t20160229_1323991.html; last accessed 29 February 2016. 
Feng, L. et al. (2014). Burden and correlates of geriatric depression in the Uyghur elderly population, observation from Xinjiang, China. PLoS One, 9, e114139.

Goes, V. F., Wazlawik, E., D'Orsi, E. and Gonzalez-Chica, D. A. (2017). Severe obesity increases the prevalence but not the incidence of depressive symptoms in the elderly-population-based cohort in Southern Brazil. International Psychogeriatric, $1-10$.

He, G., Xie, J. F., Zhou, J. D., Zhong, Z. Q., Qin, C. X. and Ding, S. Q. (2016). Depression in left-behind elderly in rural China: prevalence and associated factors. Geriatrics E Gerontology International, 16, 638-643.

Jacobson, N. C. and Newman, M. G. (2014). Avoidance mediates the relationship between anxiety and depression over a decade later. Fournal of Anxiety Disorders, 28, 437-445.

Jorm, A. F. (2000). Is depression a risk factor for dementia or cognitive decline? A review. Gerontology, 46, 219-227.

Katzman, R. et al. (1988). A Chinese version of the mini-mental state examination; impact of illiteracy in a Shanghai dementia survey. Fournal of Clinical Epidemiology, 41, 971-978.

Kim, B. S. et al. (2014). Impact of illiteracy on depression symptomatology in community-dwelling older adults. International Psychogeriatric, 26, 1669-1678.

Kuehner, C. (2003). Gender differences in unipolar depression: an update of epidemiological findings and possible explanations. Acta Psychiatrica Scandinavica, 108, 163-174.

Lawton, M. P. and Brody, E. M. (1969). Assessment of older people: self-maintaining and instrumental activities of daily living. Gerontologist, 9, 179-186.

Li, S. et al. (2012). Subjective well-being of the elderly in $\mathrm{Xi}$ Cheng district, Beijing. Shanghai Archives of Psychiatry, 24, 335-346.

Llewellyn, D. J. et al. (2010). Vitamin D and risk of cognitive decline in elderly persons. Archives of Internal Medicine, 170, 1135-1141.

Ma, L. et al. (2015). Risk factors for depression among elderly subjects with hypertension living at home in China. International fournal of Clinical and Experimental Medicine, 8, 2923-2928.

Martel, M. M. (2013). Sexual selection and sex differences in the prevalence of childhood externalizing and adolescent internalizing disorders. Psychological Bulletin, 139, 1221-1259.

Mirza, S. S. et al. (2014). Depressive symptoms predict incident dementia during short- but not long-term follow-up period. Alzheimers Dementia, 10, S323-S329.e321.

Mirza, S. S., Ikram, M. A., Bos, D., Mihaescu, R., Hofman, A. and Tiemeier, H. (2017). Mild cognitive impairment and risk of depression and anxiety: a population-based study. Alzheimers Dementia, 13, 130-139.

Moss, K., Scogin, F., Di Napoli, E. and Presnell, A. (2012). A self-help behavioral activation treatment for geriatric depressive symptoms. Aging Mental Health, 16, 625-635.

Schoevers, R. A., Beekman, A. T., Deeg, D. J., Geerlings, M. I., Jonker, C. and Van Tilburg, W. (2000). Risk factors for depression in later life; results of a prospective community based study (AMSTEL). Fournal of Affective Disorders, 59, 127-137.

Sheikh, J. I. and Yesavage, J. A. (1986). Geriatric Depression Scale (GDS-SF): recent evidence and development of a shorter version. Clinical Gerontology, 5, 165-173.

Spira, A. P., Rebok, G. W., Stone, K. L., Kramer, J. H. and Yaffe, K. (2012). Depressive symptoms in oldest-old women: risk of mild cognitive impairment and dementia. American fournal of Geriatric Psychiatry, 20, 1006-1015.

Starr, L. R. and Davila, J. (2012). Temporal patterns of anxious and depressed mood in generalized anxiety disorder: a daily diary study. Behaviour Research and Therapy, 50, 131-141.

Starr, L. R., Hammen, C., Connolly, N. P. and Brennan, P. A. (2014). Does relational dysfunction mediate the association between anxiety disorders and later depression? testing an interpersonal model of comorbidity. Depression Anxiety, 31, 77-86.

Steenland, K., Karnes, C., Seals, R., Carnevale, C., Hermida, A. and Levey, A. (2012). Late-life depression as a risk factor for mild cognitive impairment or Alzheimer's disease in 30 US Alzheimer's disease centers. Fournal of Alzheimer's Disease, 31, 265-275.

Steinert, C., Hofmann, M., Kruse, J. and Leichsenring, F. (2014). The prospective long-term course of adult depression in general practice and the community. A systematic literature review. Fournal of Affective Disorders, 152-154, 65-75.

Sun, X. Y., Li, Y. X., Yu, C. Q. and Li, L. M. (2017). Reliability and validity of depression scales of Chinese version: a systematic review. Zhonghua Liu Xing Bing Xue Za Zhi, 38, 110-116.

Taheri Tanjanai, P., Moradinazar, M. and Najafi, F. (2017). Prevalence of depression and related social and physical factors amongst the Iranian elderly population in 2012. Geriatrics \& Gerontology International, 17, 126-131.

United Nations (2014). World population ageing: 1950-2050 [cited 11 October 2014]. Available at: http://www.un.org/ esa/population/publications/worldageing19502050/.

Wang, J. L. (2004). Rural-urban differences in the prevalence of major depression and associated impairment. Social Psychiatry and Psychiatric Epidemiology, 39, 19-25.

Weyerer, S. et al. (2008). Prevalence and risk factors for depression in non-demented primary care attenders aged 75 years and older. Fournal of Affective Disorders, 111, 153-163.

WHO Ageing and Life Course (2015). Facts on ageing and life course. Available at: www.who.int/features/factfiles/ ageing/ageing_facts/en/index.html last accessed 10 January 2015.

World Health Organization (2012). Depression: A global crisis. World Mental Health Day,10 October 2012:World Federation for Mental Health; 2012:14. Available at: http://wfmh.com/wp-content/uploads/2013/11/ 2012_wmhday_english.pdf last accessed 14 January 2015.

Xiao, S. Y. (1993). The social support rate scale. Chinese fournal of Psychology, 7 (Suppl.), 42-46.

Xie, L. Q., Zhang, J. P., Peng, F. and Jiao, N. N. (2010). Prevalence and related influencing factors of depressive symptoms for empty-nest elderly living in the rural area of 
YongZhou, China. Archives of Gerontology and Geriatrics, 50, 24-29.

Xu, H., Xiao, S. and Chen, J. (2000). Epidemiological study on committed suicide among the elderly in some urban and rural areas of Hunan Province. Chinese Mental Health, 14, 121-124.

Xu, Y. et al. (2016). Decomposing socioeconomic inequalities in depressive symptoms among the elderly in China. $B M C$ Public Health, 16, 1214.

Yusuf, A. J., Isa, M. S., Amedu, M. A., Nuhu, F. T. and Garko, S. B. (2013). Late life depression among elderly hypertensive patients. Nigerian Postgraduate Medical fournal, 20, 208-213.

Zhang, B. and Li, J. (2011). Gender and marital status differences in depressive symptoms among elderly adults: the roles of family support and friend support. Aging Mental Health, 15, 844-854.

Zhao, Y. et al. (2017). Associations of self-neglect with quality of life in older people in rural China: a cross-sectional study. International Psychogeriatric, 1-12.

Zung, W. W. (1971). A rating instrument for anxiety disorders. Psychosomatics, 12, 371-379. 